\title{
PERBANDINGAN ESTIMASI ANGGARAN BIAYA DENGAN METODE SNI DAN BOW
}

\author{
Mahardika Rahmawan Putra ${ }^{1)}$, Nur Azizah Affandy ${ }^{2)}$ \\ ${ }^{1}$ Program Studi Teknik Sipil Fakultas Teknik Universitas Islam Lamongan \\ ${ }^{2}$ Fakultas Teknik Program Studi Teknik Sipil Univesitas Islam Lamongan, \\ email:nurazizah_5@yahoo.com
}

\begin{abstract}
The concept of drafting the Budget Plan (RAB) project is done based on an analysis of each constituent component for every work items on the entire project. This calculation analysis use two methods, SNI method and BOW method. This calculation uses the analysis of unit price in 2016. From the calculation, the analysis of unit prices in the construction of religious ministry office in Lamongan Regencyshows that the budget estimation using SNI method is more economical. SNI method has more economical budget in the amount of Rp. 709,743,313.65 compared to BOW method, amountedRp 1,759,104,217.65. The difference of those two methods is Rp. 1,049,360,904. This result occurs because the coefficient for SNI method is lower than the BOW method.
\end{abstract}

Keywords: RAB, Unit Price, SNI method, Method BOW

\section{PENDAHULUAN}

Pelaksanaan sebuah proyek konstruksi sangat berkaitan dengan proses manajemen didalamnya. Pada tahapan itu, pengelolaan anggaran biaya untuk melaksanakan pekerjaan tersebut, perlu dirancang dan disusun sedimikian rupa berdasarkan sebuah konsep estimasi yang terstruktur sehingga menghasilkan nilai estimasi rancangan yang tepat dalam arti ekonomis. Serta dapat di perhitungkan untuk melakukan sebuah pembangunan gedung kantor atau perusahaan agar tidak terjadi adanya perselisihan.

Nilai estimasi anggaran yang disusun selanjutnya dikenal dengan istilah Rencana Aanggaran Biaya (RAB) Proyek, yang mempunyai fungsi dan manfaat lebih lanjut dalam hal mengendalikan sumber daya material, tenaga kerja, peralatan dan waktu pelaksanaan proyek sehingga pelaksanaan kegiatan proyek yang dilakukan akan mempunyai nilai efisiensi dan efektivitas.

Konsep penyusunan Rencana Anggaran Biaya (RAB) Proyek, pada pelaksanaannya didasarkan pada sebuah analisa masing- masing komponen penyusunnya (material, upah dan peralatan) untuk tiap-tiap ítem pekerjaan yang terdapat dalam keseluruhan proyek. Hasil analisa komponen tersebut pada akhirnya akan menghasilkan Harga Satuan Pekerjaan (HSP) per item yang menjadi dasar dalam menentukan nilai estimasi biaya pelaksanaan proyek keseluruhan dengan mekonversikannya ke dalam total volume untuk tiap ítem pekerjaan yang dimaksud. Biaya awal digunakan untuk studi kelayakan, alternatif desain yang mungkin, dan pemilihan desain yang optimal untuk sebuah proyek. Hal yang penting dalam pemilihan metode estimasi biaya awal haruslah akurat, mudah, dan tidak mahal dalam penggunaannya.

Berdasarkan alasan di atas maka penulis tertarik untuk melakukan penelitian serta membahas masalah tersebut yang dituangkan dalam skripsi yang berjudul: "Analisa Harga Satuan Berdasarkan Metode SNI dan BOW pada Pembangunan Kantor Kementrian Agama Kabupaten Lamongan". Adapun tujuan penelitian secara khusus adalah untuk mengetahui perhitungan Rencana Anggaran 
Biaya dengan metode SNI dan BOW serta mengetahui perbedaan hasil perhitungan anggaran biaya antara metode analisa SNI dan BOW tersebut.

\section{METODE PENELITIAN}

Rencana Anggaran Biaya rehabilitasi gedung dapat dihitung dengan dua metode, yaitu metode SNI dan metode BOW.

\section{Rencana Anggaran Biaya}

Secara umum pengertian Rencana Anggaran Biaya (RAB) Proyek adalah nilai estimasi biaya yang harus disediakan untuk pelaksanaan sebuah kegiatan proyek.

\section{Metode SNI}

SNI merupakan pembaharuan dari analisa BOW (Burgeslijke Openbare Werken) 1921, dengan kata lain bahwasanya analisa SNI merupakan analisa BOW yang diperbaharui. Analisa SNI ini dikeluarkan oleh Pusat Penelitian Dan Pengembangan Pemukiman. Sistem penyusunan biaya dengan menggunakan analisa SNI ini hampir sama dengan sistem perhitungan dengan menggunakan analisa BOW. Prinsip yang mendasar pada metode SNI adalah, daftar koefisien bahan, upah dan alat sudah ditetapkan untuk menganalisa harga atau biaya yang diperlukan dalam membuat harga satu satuan pekerjaan bangunan. Dari ketiga koefisien tersebut akan didapatkan kalkulasi bahan-bahan yang diperlukan, kalkulasi upah yang mengerjakan, serta kalkulasi peralatan yang dibutuhkan. Komposisi perbandingan dan susunan material, upah tenaga dan peralatan pada satu pekerjaan sudah ditetapkan, yang selanjutnya dikalikan dengan harga material, upah dan peralatan yang berlaku dipasaran.

Dari data kegiatan tersebut di atas, menghasilkan produk sebuah analisa yang dikukuhkan sebagai Standar Nasional Indonesia (SNI) pada tahun 19911992, dan pada tahun 2001 hingga sekarang, SNI ini disempurnakan dan diperluas sasaran analisa biayanya.

Contoh perhitungan rencana anggaran biaya dengan metode SNI yaitu:

Harga satuan $1 \mathrm{~m} 3$ pekerjaan membuat beton dengan mutu K-225:
Bahan :

$0,65 \mathrm{~m}^{3}$ Kerikil @ $75.000=$ Rp. 48.750,00

7,42 kg Semen @ 56.900 = Rp. 422.198,00

PC $50 \mathrm{~kg}$

$0,65 \mathrm{~m}^{3}$ Pasir @ $50.000 \quad$ =Rp. $32.500,00$

Jumlah harga bahan $\quad=$ Rp. 503.448,00

Upah :

0.275 Tukang Batu @ $72.900=$ Rp. 20.047,5

0,028 Kepala@ @ $87.500=$ Rp. 2.450,00 Tukang Batu

1,65 Pekerja

@ $45.000=$ Rp. $74.250,00$

0,083 Mandor

@ 65.600

$=$ Rp.5.444,8,0

Jumlah harga upah

= Rp. 102.192,3

Peralatan :

0,4819 Concrete @ $@ 36.480 \quad=$ Rp.17.579,89 Mixer

0,0633 Water Tanker

0,4819 Concrete Vibrator

1,0000 Alat Bantu

@ $117.765=$ Rp. $7.454,53$

@ $21.740=\mathrm{Rp} \cdot 10.476,51$

@ $2.050=$ Rp. $2.050,00$

Jumlah harga alat

$=$ Rp. 37.560,93

Harga satuan $1 \mathrm{~m}^{3}$ pekerjaan membuat beton dengan mutu K-225 adalah :

= Jumlah harga barang + Jumlah harga upah + Jumlah harga peralatan

$=$ Rp. 503,448,00 + Rp. 102.192,3 +

Rp.37.560,93

$=$ Rp. $643 \cdot 201,23$

\section{Metode BOW}

BOW (Burgeslijke Openbare Werken) adalah suatu ketentuan dan ketetapan umum yang ditetapkan Dir. BOW pada tanggal 28 Februari 1921 nomor 5372 A pada jaman Belanda. Dalam analisa BOW, telah ditetapkan angka jumlah tenaga kerja dan bahan untuk suatu pekerjaan.Prinsip yang terdapat pada metode BOW mencangkup daftar koefisien upah dan bahan yang telah ditetapkan. Keduanya menganalisa harga (biaya) yang diperlukan untuk harga satuan pekerjaan bangunan. Dari koefisien tersebut akan didapatkan kalkulasi bahan-bahan yang diperlukan dan kalkulasi upah yang mengerjakan. Komposisi perbandingan dan susunan material serta tenaga kerja pada suatu pekerjaan sudah ditetapkan yang selanjutnya dikalikan harga material dan upah yang berlaku pada saat itu.

Analisa BOW biasanya hanya dipakai untuk pekerjaan yang bersifat padat karya dan 
memakai peralatan konvensional (BOW, 1921), seperti pacul, engkrak,cetok, palu dan peralatan sederhana lainnya sehingga sampai sekarang masih digunakan oleh pemerintah dalam menghitung pembiayaan suatu kegiatan (proyek) yang berskala kecil. Namun didalam BOW juga ada analisa harga satuan pekerjaan untuk pekerjaan yang menggunakan alat berat, dan tentu saja untuk pekerjaan yang berskala besar.

Contoh perhitungan analisa anggaran biaya dengan metode BOW adalah:

Harga satuan $1 \mathrm{~m} 3$ pekerjaan membuat beton dengan mutu K-225:

\begin{tabular}{|c|c|c|}
\hline . & & \\
\hline $0,96 \mathrm{~m}^{3}$ Kerikil & @ 75.000 & $=$ Rp. $\quad 72.000,00$ \\
\hline $\begin{array}{c}\text { 8,17Zak Semen PC } \\
50 \mathrm{~kg}\end{array}$ & @ 56.900 & $=$ Rp. $484.873,00$ \\
\hline $\begin{array}{l}0,54 \mathrm{~m}^{3} \text { Pasir } \\
\text { Jumlah harga bahan }\end{array}$ & @ 50.000 & $\begin{array}{l}=\text { Rp. } \quad 27.000,00 \\
=\text { Rp. } \mathbf{5 6 3 . 8 7 3 , 0 0}\end{array}$ \\
\hline Upah : & & \\
\hline 1,00 Tukang Batu & @ 72.900 & $=$ Rp. $\quad 72.900,00$ \\
\hline $\begin{array}{l}0,10 \text { Kepala } \\
\text { Tukang Batu }\end{array}$ & @ 87.500 & $=$ Rp. $\quad 8.750,00$ \\
\hline 6,00 Pekerja & @ 45.000 & $=$ Rp. $270.000,00$ \\
\hline 0,30 Mandor & @ 65.600 & $=$ Rp. $\quad 19.680,00$ \\
\hline Jumlah harga upah & & $=$ Rp. $371.330,00$ \\
\hline Peralatan : & & \\
\hline $\begin{array}{l}\text { 0,4819 Concrete } \\
\text { Mixer }\end{array}$ & @ 36.480 & $=$ Rp.17.579,8900 \\
\hline $\begin{array}{c}0,0633 \text { Water } \\
\text { Tanker }\end{array}$ & @ 117.765 & $=$ Rp. $7 \cdot 545,5300$ \\
\hline $\begin{array}{c}\text { 0,4819 Concrete } \\
\text { Vibrator }\end{array}$ & @ 21.740 & $=$ Rp. $10 \cdot 476,5110$ \\
\hline $\begin{array}{l}\text { 1,0000 Alat Bantu } \\
\text { Jumlah harga alat }\end{array}$ & 2.050 & $\begin{array}{ll}=\text { Rp. } & 2 \cdot 050,0000 \\
=\text { Rp. } & 37.560,931\end{array}$ \\
\hline
\end{tabular}

Harga satuan $1 \mathrm{~m}^{3}$ pekerjaan beton mutu $\mathrm{K}$ 225 adalah :

= Jumlah harga bahan + Jumlah harga upah + Jumlah harga peralatan

$=$ Rp. $563 \cdot 873,00+$ Rp. $371 \cdot 330,00+$

Rp.37.560,93

$=$ Rp. $972.763,93$

\section{Prosentase Bobot Pekerjaan}

Yang dimaksud dengan Prosentase

Bobot Pekerjaan ialah besarnya persen pekerjaan siap, dibanding dengan pekerjaan siap seluruhnya. Pekerjaan siap seluruhnya dinilai $100 \%$.

Prosentase bobot pekerjaan merupakan besarnya nilai prosentase tiap item-item pekerjaan, berdasarkan perbandingan antara anggaran biaya pekerjaan dengan harga bangunan.

Prosentase Bobot Pekerjaan dibuat apabila Rencana Anggaran Biaya selesai kita susun, karena dasar pembuatan Prosentase Bobot Pekerjaan adalah Rencana Anggran Biaya (RAB). Keuntungan dengan dibuatnya Prosentase Bobot Pekerjaan salah satunya adalah untuk Penjadwalan Pelaksanaan Pekerjaan sehingga mempermudah kontrol terhadap pekerjaan yang sedang kita kerja kan dan efeknya proyek tidak akan mengalami keterlambatan.

Cara Menghitung Prosentase Bobot Pekerjaan Data - data yang diperlukan :

Volume Pekerjaan

Harga Satuan pekerjaan

Nilai Proyek Fisik ( Nilai sesuai RAB tidak termasuk pajak $10 \%$ )

Contoh Perhitungan Prosentase Bobot

Pekerjaan

Pekerjaan Plesteran $1: 2$

Volume Pekerjaan Plesteran $1: 2=1500 \mathrm{~m}^{2}$

Harga Satuan Pekerjaan Plesteran 1:2=Rp.

27.000,oo

Nilai Proyek Fisik ( Nilai sesuai RAB tidak termasuk pajak $10 \%$ ) = Rp. 450.000.000,00 (angka diatas hanya contoh )

Maka Prosentase Bobot Pekerjaan untuk

Pekerjaan Plesteran 1:2 adalah :

$1500 \mathrm{~m}^{2}$ x Rp. $27.000,00$

$$
\begin{aligned}
& \text { Rp. } 450.000 .000,00 \\
& =9 \%
\end{aligned}
$$

Jadi apabila Pekerjaan Plesteran 1:2 selesai semuanya, Prosentase Bobot Pekerjaannya adalah $9 \%$ terhadap pekerjaan seluruhnya.

\section{Langkah-langkah Membuat RAB}

RAB (Rencana Angaran Biaya) adalah banyaknya biaya yang dibutuhkan baik upah maupun bahan dalam sebuah perkerjaan proyek konstruksi, baik Rumah, gedung, jembatan, dan lain-lain, nah berikut ini tak berikan langkah-langkah cara menghitung RAB agar anda dapat lebih cermat menghitung $\mathrm{RAB}$ melalui tahap-demi tahap, sehingga dapat mengurangi pembengkakan 
biaya sehingga kita bisa hasil yg maksimal dengan biaya yang efisien.

Komponen Penyusun Rencana Anggaran Biaya

1.Komponen biaya langsung (Direct Cost)

2.Komponen biaya tidak langsung (Indirect Cost)

\section{HASIL DAN PEMBAHASAN}

Sesuai rekapitulasi biaya maka jenis-jenis pekerjaan proyek Pembangunan Kantor Kementrian Agama Kabupaten Lamongan adalah sebagai berikut :

- Pekerjaan Persiapan

- Pekerjaan Beton

- Pekerjaan Pasangan

- Pekerjaan Kusen Dan Pintu

- Pekerjaan Kunci Dan Kaca

- Pekerjaan Lantai Dan Keramik

- Pekerjaan Atap

- Pekerjaan Plafond

- Pekerjaan Pengecatan

- Pekerjaan Sanit Air

- Pekerjaan Listrik

Rehabilitasi Gedung Meliputi Pekerjaan :

- Pekerjaan Pendahuluan

- Pekerjaan Tanah

- Pekerjaan Beton

Analisa Perhitungan

Berikut adalah data-data yang didapat dan langkah-langkah yang dilakukan dalam melakukan analisa perhitungan pada Pembangunan Kantor Kementrian Agama Kabupaten Lamongan :

1.Data Proyek

Yaitu data-data yang didapat pada proyek Pembangunan Kantor Kementrian Agama Kabupaten Lamongan.

2.Data Upah Pekerja

Yaitu data upah pekerja yang dipakai pada proyek Pembangunan Kantor Kementrian Agama Kabupaten Lamongan berdasarkan HSPK (Harga Satuan Pokok Kegiatan) Kota Lamongan.

3.Data Harga Material

Adapun data harga material yang didapat berdasarkan HSPK (Harga Satuan Pokok Kegiatan) Kota Lamongan.
4. Data Volume Pekerjaan

Yaitu data volume pekerja yang dipakai pada proyek Pembangunan Kantor Kementrian Agama Kabupaten Lamongan berdasarkan HSPK (Harga Satuan Pokok Kegiatan) Kota Lamongan.

\section{Analisa Harga Satuan Berdasarkan Metode SNI}

Data analisa harga satuan berikut ini berdasarkan metode SNI sesuai dengan HSPK tahun 2016:

\begin{tabular}{|c|c|c|c|c|c|}
\hline \multirow{2}{*}{$\begin{array}{l}\text { JENIS } \\
\text { PEKERJAAN }\end{array}$} & \multirow{2}{*}{ KOEF } & \multirow{2}{*}{ STN } & \multirow{2}{*}{$\begin{array}{l}\text { HARGA } \\
\text { BAHAN }\end{array}$} & JUMLAH & $\begin{array}{l}\text { HARGA } \\
\text { SATUAN }\end{array}$ \\
\hline & & & & $(\mathrm{Rp})$ & (Rp) \\
\hline
\end{tabular}

ANALISA BIAYA KONSTRUKSI PEKERJAAN TANAH

1 M3 GALIAN TANAH BIASA SEDALAM 1 METER

$$
\begin{array}{lllll}
\text { Pekerja } & 0,7500 & \text { Oh } & 65.000,00 & 48.750,00 \\
\text { Mandor } & 0,0250 & \text { Oh } & 90.000,00 & 2.250,00 \\
\hline
\end{array}
$$

\begin{tabular}{ll} 
Jumlah & $51.000,00$ \\
\hline Dibulatkan & $51.000,00$ \\
\hline
\end{tabular}

1 M' GALIAN STROUS $\varnothing 30 \mathrm{CM}$ :

$\begin{array}{lllll}\text { Pekerja } & 0,2450 & \text { Oh } & 65.000,00 & 15.925,00 \\ \text { Mandor } & 0,0243 & \text { Oh } & 90.000,00 & 2.187,00\end{array}$

Jumlah $\quad 18.112,00$

1 M3 URUGAN KEMBALI

$$
\begin{array}{lllll}
\text { Pekerja } & 0,2500 & \text { Oh } & 65.000,00 & 16.250,00 \\
\text { Mandor } & 0,0083 & \text { Oh } & 90.000,00 & 750,00 \\
\cline { 3 - 4 }
\end{array}
$$

\section{Analisa Harga Satuan Berdasarkan Metode BOW}

Data analisa harga satuan berikut ini berdasarkan metode BOW sesuai dengan koefisien dari Buku Anonymous, 2003, Analisa Upah dan Bahan (Analisis BOW ), PT. Bumiaksara, Jakarta. dengan bahan satuan pekerja tahun 2016 : 


\begin{tabular}{|c|c|c|c|c|c|}
\hline \multirow{2}{*}{$\begin{array}{l}\text { JENIS } \\
\text { PEKERJAAN }\end{array}$} & \multirow{2}{*}{ KOEF } & \multirow{2}{*}{ STN } & \multirow{2}{*}{$\begin{array}{l}\text { HARGA } \\
\text { BAHAN }\end{array}$} & \multirow{2}{*}{$\begin{array}{l}\text { JUMLAH } \\
\text { (Rp) }\end{array}$} & \multirow{2}{*}{$\begin{array}{l}\text { HARGA } \\
\text { SATUAN } \\
(\mathrm{Rp})\end{array}$} \\
\hline & & & & & \\
\hline \multicolumn{6}{|c|}{ ANALISA BIAYA KONSTRUKSI PEKERJAAN TANAH } \\
\hline \multicolumn{6}{|c|}{$1 \mathrm{M} 3$ Galian tanah biasa sedalam 1 meter } \\
\hline Pekerja & 0,7500 & $\mathrm{Oh}$ & $65.000,00$ & $48.750,00$ & \\
\hline \multirow[t]{3}{*}{ Mandor } & 0,0250 & Oh & $90.000,00$ & $\underline{2.250,00}$ & \\
\hline & & & & Jumlah & $51.000,00$ \\
\hline & & & & Dibulatkan & $51.000,00$ \\
\hline \multicolumn{6}{|c|}{1 M' GALIAN STROUS Ø $30 \mathrm{~cm}$ : } \\
\hline Pekerja & 0,2450 & $\mathrm{Oh}$ & $65.000,00$ & $15.925,00$ & \\
\hline \multirow[t]{3}{*}{ Mandor } & 0,0243 & Oh & $90.000,00$ & $\underline{2.187,00}$ & \\
\hline & & & & Jumlah & $18.112,00$ \\
\hline & & & & Dibulatkan & $18.100,00$ \\
\hline \multicolumn{6}{|c|}{$1 \mathrm{M} 3$ Urugan kembali } \\
\hline Pekerja & 0,2500 & $\mathrm{Oh}$ & $65.000,00$ & $16.250,00$ & \\
\hline \multirow[t]{3}{*}{ Mandor } & 0,0083 & Oh & $90.000,00$ & $\underline{750,00}$ & \\
\hline & & & & Jumlah & $17.000,00$ \\
\hline & & & & Dibulatkan & $17.000,00$ \\
\hline
\end{tabular}

Rekapitulasi Rencana Anggaran Biaya (RAB)

Berikut adalah rekapitulasi dari Rencana Anggaran Biaya (RAB) berdasarkan metode SNI dan BOW:

\begin{tabular}{|c|c|c|c|}
\hline NO & $\begin{array}{c}\text { URAIAN } \\
\text { PEKERJAAN }\end{array}$ & $\begin{array}{c}\text { JUMLAH } \\
\text { HARGA SNI }\end{array}$ & $\begin{array}{c}\text { JUMLAH } \\
\text { HARGA BOW }\end{array}$ \\
\hline I & TOTAL & $\operatorname{Rp} 709,743,313$ & $\operatorname{Rp} 1,759,104,217$ \\
\hline II & $\begin{array}{l}\text { PPN } 10 \%(1) \\
\text { TOTAL } \\
\text { TERMASUK }\end{array}$ & $\operatorname{Rp} 70,974,331$ & $\operatorname{Rp} 175,910,421$ \\
\hline III & $\begin{array}{l}\text { PPN } \\
\text { DI }\end{array}$ & Rp 780,717,645 & Rp 1,935,014,639 \\
\hline IV & BULATKAN & Rp 780,717,650 & Rp $1,935,014,650$ \\
\hline
\end{tabular}

Rekapitulasi di atas menunjukkan bahwa total harga dari perhitungan Metode SNI lebih ekonomis di banding dengan metode BOW. Menghitung Bobot Prosentase Pekerjaan Dalam Menghitung Bobot Prosentase ini ada 2 Rencana Anggaran Biaya yaitu dengan metode SNI dan metode BOW.

\section{Prosentase Metode SNI}

Contoh Perhitungan Prosentase Bobot

Pekerjaan

Pekerjaan Persiapan
Volume Pekerjaan Persiapan $1.00 \mathrm{~m}^{2}$

Harga Satuan Pekerjaan Persiapan $=\mathrm{Rp}$. 250.000,00

Nilai Proyek Fisik ( Nilai sesuai RAB tidak termasuk pajak 10\% ) = Rp. 709.743.313,65

Maka Prosentase Bobot Pekerjaan untuk Pekerjaan Plesteran 1:2 adalah :

$=$ Rp. $250.000,00 /$ Rp. $709.743 .313,65 \times 100 \%$ $=0,03 \%$

Jadi apabila Pekerjaan Persiapan selesai semuanya, Prosentase Bobot Pekerjaannya adalah $0,03 \%$ terhadap pekerjaan seluruhnya.

\begin{tabular}{|c|c|c|}
\hline NO & URAIAN PEKERJAAN & $\begin{array}{c}\text { BOBOT } \\
\text { PROSENTASE } \\
(\%) \\
\end{array}$ \\
\hline 1 & PEK. PERSIAPAN & 0,03 \\
\hline 2 & PEKERJAAN. BETON & 16,6 \\
\hline 3 & $\begin{array}{l}\text { PEKERJAAN PASANGAN } \\
\text { PEKERJAAN }\end{array}$ & 10,34 \\
\hline 4 & $\begin{array}{l}\text { DAN PINTU } \\
\text { PEKERJAAN KUNCI DAN }\end{array}$ & 5,14 \\
\hline 5 & $\begin{array}{l}\text { KACA } \\
\text { PEKERJAAN LANTAI \& }\end{array}$ & 1,6 \\
\hline 6 & KERAMIK & 8,6 \\
\hline 7 & PEKERJAAN ATAP & 34,37 \\
\hline 8 & PEKERJAAN PLAFOND & 1,77 \\
\hline 9 & $\begin{array}{l}\text { PEKERJAAN } \\
\text { PENGECATAN }\end{array}$ & 2,9 \\
\hline 10 & PEKERJAAN SANITAIR & 1,78 \\
\hline \multirow[t]{2}{*}{11} & PEK. LISTRIK & 0,72 \\
\hline & REHABILITASI GEDUNG & \\
\hline 1 & PEK. PENDAHULUAN & 0,25 \\
\hline 2 & PEKERJAAN TANAH & 0,52 \\
\hline \multirow[t]{2}{*}{3} & PEKERJAAN. BETON & 15,37 \\
\hline & JUMLAH & 100 \\
\hline
\end{tabular}

\section{Prosentase Metode BOW}

Hasil perhitungan Bobot Prosentase menurut Metode BOW :

Contoh Perhitungan Prosentase Bobot

Pekerjaan

Pekerjaan Persiapan

Volume Pekerjaan Persiapan : 1,00

Harga Satuan Pekerjaan Persiapan : 250.000

Nilai Proyek Fisik ( Nilai sesuai RAB tidak termasuk pajak 10\% ) = Rp. 1.759.104.217,65

Maka Prosentase Bobot Pekerjaan untuk Pekerjaan Persiapan adalah : 
$=$ Rp. $250.000,00 /$ Rp. $1.759 \cdot 104.217,65 \times 100 \%$ $=0,02 \%$

Jadi apabila Pekerjaan Persiapan selesai semuanya, Prosentase Bobot Pekerjaannya adalah $0,02 \%$ terhadap pekerjaan seluruhnya.

Tabel Prosentase Metode BOW

\begin{tabular}{|c|c|c|}
\hline NO & $\begin{array}{l}\text { URAIAN } \\
\text { PEKERJAAN }\end{array}$ & $\begin{array}{c}\text { BOBOT } \\
\text { PROSENTASE } \\
(\%) \\
\end{array}$ \\
\hline 1 & $\begin{array}{l}\text { PEK. PERSIAPAN } \\
\text { PEKERJAAN. }\end{array}$ & 0,02 \\
\hline 2 & $\begin{array}{l}\text { BETON } \\
\text { PEKERJAAN }\end{array}$ & 11,73 \\
\hline 3 & $\begin{array}{l}\text { PASANGAN } \\
\text { PEKERJAAN KUSEN }\end{array}$ & 5,18 \\
\hline 4 & $\begin{array}{l}\text { DAN PINTU } \\
\text { PEKERJAAN KUNCI }\end{array}$ & 4,93 \\
\hline 5 & $\begin{array}{l}\text { DAN KACA } \\
\text { PEKERJAAN } \\
\text { LANTAI }\end{array}$ & 0,64 \\
\hline 6 & KERAMIK & 4,39 \\
\hline 7 & $\begin{array}{l}\text { PEKERJAAN ATAP } \\
\text { PEKERJAAN }\end{array}$ & 59,16 \\
\hline 8 & $\begin{array}{l}\text { PLAFOND } \\
\text { PEKERJAAN }\end{array}$ & 0,71 \\
\hline 9 & $\begin{array}{l}\text { PENGECATAN } \\
\text { PEKERJAAN }\end{array}$ & 1,17 \\
\hline 10 & SANITAIR & 0,72 \\
\hline \multirow[t]{2}{*}{11} & PEK. LISTRIK & 0,29 \\
\hline & $\begin{array}{l}\text { REHABILITASI GED } \\
\text { PEKERJAAN }\end{array}$ & JNG \\
\hline 1 & $\begin{array}{l}\text { PENDAHULUAN } \\
\text { PEKERJAAN }\end{array}$ & 0,1 \\
\hline 2 & $\begin{array}{l}\text { TANAH } \\
\text { PEKERJAAN. }\end{array}$ & 0,22 \\
\hline \multirow[t]{2}{*}{3} & BETON & 10,74 \\
\hline & JUMLAH & 100 \\
\hline
\end{tabular}

Dari kedua Bobot Prosentasi di atas juga memiliki perbedaan yang lumayan cukup besar. Dan dari sini mungkin bias lebih memilih untuk menggunakan metode yang tepat dalam mempersiapkan penyusunan Rencana Anggaran Biaya.

\section{KESIMPULAN}

Dari hasil perhitungan pada pembahasan tugas akhir tentang "Analisis Rencana Anggaran Biaya pada Pembangunan Kantor Kementrian Agama Kabupaten Lamongan" maka diperoleh kesimpulan bahwa hasil estimasi anggaran biaya lebih ekonomis adalah dengan metode SNI. Metode SNI mempunyai anggaran biaya yang lebih ekonomis yaitu sebesar Rp. 709.743.313,65dibandingkan dengan metode BOW yaitu sebesar Rp 1.759.104.217,65. Dari kedua metode tersebut mendapatkan selisih yang sangat besar yaitu Rp. 1.049.360.904. Hasil ini terjadi karena koefisien untuk metode SNI lebih rendah dibandingkan dengan metode BOW.

\begin{tabular}{llll}
\hline \multicolumn{1}{c}{ URAIAN } & \multicolumn{1}{c}{ JUMLAH } & \multicolumn{1}{c}{ JUMLAH } \\
NO & PEKERJAAN & HARGA SNI & HARGA BOW \\
\hline & & & \\
I & TOTAL & $\operatorname{Rp} 709,743,313$ & $\mathrm{Rp} 1,759,104,217$ \\
II & PPN 10\% (1) & $\operatorname{Rp~70,974,331}$ & $\mathrm{Rp} \mathrm{175,910,421}$ \\
III & TOTAL & $\mathrm{Rp} 780,717,645$ & $\mathrm{Rp} 1,935,014,639$ \\
& TERMASUK & & \\
& PPN & & \\
IV & DIBULATKAN & $\mathrm{Rp} 780,717,650$ & $\mathrm{Rp} 1,935,014,650$ \\
\hline
\end{tabular}

\section{REFERENSI}

Anonymous, 2003, Analisa Upahdan Bahan (analisisBOW ), PT. Bumiaksara, Jakarta.

Bachtiar Ibrahim dalam bukunya Rencana dan Estimate Real of Cost, 1993

Harga Satuan Pekerjaan (HSPK),2016 KabupatenLamongan

Ir. A. Soedradjat Sastraatmadja, 1984, dalam bukunya "Analisa Anggaran Pelaksanaan"

J. A. Mukomoko, dalam bukunya Dasar PenyusunanAnggaranBiayaBangunan 1987

John W. Niron dalam bukunya Pedoman PraktisAnggaran dan Borongan Rencana Anggaran Biaya Bangunan, 1992

Rencana Anggaran Biaya (RAB) Gedung Kementerian Agama Kabupaten Lamongan.

http://pengertiandefinisi.com/pengertiananalisa-menurut-ahli/ di akses pada tanggal 5 Juni 201623.54

http://sipilworld.blogspot.com/2013/03/estim asi-biaya-konstruksi-di-dalam.html diakses pada tanggal 1 juni 201616.38

http://thexandwi.blogspot.co.id/2009/11/caramenghitung-prosentase-bobot.html diakses pada tanggal 06 Juni 201621.34 
http://rudiniaciel.blogspot.com/2012/05/car a-menghitung-volume-pekerjaan.html diakses pada tanggal 06 Juni 201621.34

http://pengertiandefinisi.com/pengertiananalisamenurut-ahli/di akses pada tanggal 17 Juni 201623.54

http://insinyursipil.blogspot.com/2013/02/lang kahlangkah-membuat-rab.html di akses pada tanggal 06 Juni 2016 
Halaman ini sengaja dikosongkan 